\title{
Association of Dribbling with Linear and Non-linear Sprints in Young Soccer Players of Bangladesh
}

\author{
Muhammad Shahidul Islam*, Brajanath Kundu
}

\begin{abstract}
Aim: The study was designed to examine the relationships between field-based dribbling performance [measured using the Mor-Christian general soccer ability skill test] and selected field-based short sprint test performances in Bangladeshi youth soccer players. Materials and Methods: The study was conducted by 60 male soccer players aged 16 to 19 years. Repeated sprint ability (RSA) and Illinois agility test evaluated for non-linear short sprints. The linear short sprint was evaluated by a 20-metre linear sprint experiment. Data was analyzed using Pearson correlation of coefficient and multiple regression equations. Results: The moderate positive relationship was found between the Mor-Christian dribbling performance and the selected change of direction sprinting. The results also showed that the $20 \mathrm{~m}$ linear sprint with Mor-Christian dribbling performance had a statistically non-significant positive small correlation. Moreover, the four independent variables selected in the regression equation (RSA mean time, RSA best time, Illinois agility test, and $20 \mathrm{~m}$ sprint test) explain $31.8 \%$ of the total dribbling performance variability. Conclusion: Both linear and non-linear sprinting are relevant motor fitness capabilities linked to soccer dribbling performance. Agility-based physical capacities were found to correlate more highly with dribbling. It is suggested that a proper training schedule be established and enforced in order to improve dribbling efficiency.
\end{abstract}

Key words: Dribbling, Sprint, Soccer, Agility, Fitness.

\section{Muhammad Shahidul Islam*, Brajanath Kundu Department of Physical Education and Sport Science, Visva-Bharati University, Santiniketan, West Bengal, INDIA.}

\section{Correspondence}

Mr. Muhammad Shahidul Islam, Research Scholar, Department of Physical Education and Sport Science, VisvaBharati University, Santiniketan-731235, West Bengal, INDIA.

Mobile no: +91 9674993696

Email: jewel.soccer@yahoo.com

History

- Submission Date: 14-04-2020

- Revised Date: 08-06-2020

- Accepted Date: 16-07-2020

DOI : 10.5530/ijmedph.2020.3.21

Article Available online

http://www.ijmedph.org/v10/i3

\section{Copyright}

(C) 2020 Phcog.Net. This is an openaccess article distributed under the terms of the Creative Commons Attribution 4.0 International license.

\section{INTRODUCTION}

Soccer is characterized as a repetitive high-intensity intermittent team game $e^{1-3}$ that requires a variety of athletic activities with or without a ball. ${ }^{4-6}$ Attacking and defensive soccer skills attract people. A variety of attacking skills can influence the outcome of a match, ${ }^{7}$ and dribbling is one of them. ${ }^{8}$ Dribbling helps the team to keep possession of the ball and beat the opponent. On average, soccer players perform more than 700 turns and swerve at different angles. ${ }^{9}$ Physical fitness, therefore, plays a key role in improving field performance. ${ }^{10,11}$ Quick start and stops and quick changes in direction are fundamental for good performance in athletics. ${ }^{12}$ Alanazi $(2015)^{13}$ stated, "The Illinois agility test (IAT) was used to determine the ability to accelerate, decelerate, turn in different directions and run at different angles" (p.29). As a result, field tests can be used by the coach to determine the fitness of the athletes. Repeated sprinting capability (RSA) and Illinois agility test are validated sprint tests to assess the ability of the player to sprint linearly and to perform lateral alterations. ${ }^{14}$ On the other hand, linear sprint helps to create the chance to score. ${ }^{15}$ Scoring players $(\mathrm{N}=161)$ perform straight sprints prior to all $45 \%$ of the goals analyzed..$^{16} \mathrm{~A}$ recent study of soccer games has shown that the mean duration of sprint is between 2 and $4 \mathrm{~s}^{17,18}$ which is also comparable with $20 \mathrm{~m}$ sprint

timing. Presumably, researchers have agreed that linear sprints are the most frequent actions taken in the attacking third of the field. Without a doubt, soccer is one of the fastest games in the world and the movement of soccer is so complex and intelligible ${ }^{19}$ that players' fitness plays a crucial role in the fluidity of the game. Agility, change of direction sprint, straight sprints are the respective fitness feature. So, the researchers want to understand which kind of sprint is closest to soccer dribbling ability.

\section{OBJECTIVES}

The objective of this study was to analyze the relationships between the dribbling tests and selected short sprint test scores.

\section{MATERIALS AND METHODS}

Participants in this study were chosen from national youth soccer players in Bangladesh. A total of 60 male outfield players (Defender=17, Midfielder, and Attacker $=43$ ) aged between 16-19 years with a mean value of $16.65, \mathrm{SD} \pm 1.36$ years were chosen for this study. The purposive sampling technique was used to select the participants. Players had at least three years of active competitive playing experience and their Body Mass Index (BMI) in the standard range (18.5$\left.24.9 \mathrm{~kg} / \mathrm{m}^{2}\right)$. Participants were informed verbally and

Cite this article : Islam MS, Kundu B. Association of Dribbling with Linear and Non-linear Sprints in Young Soccer Players of Bangladesh. Int J Med Public Health. 2020;10(3):100-3. 
in writing of the nature and requirements of the study. Written informed consent was obtained from all participants prior to the completion of the health questionnaire. The "Board of Studies," Department of Physical Education and Sport Science, Visva-Bharati University, carried out this study and forwarded it to the Institutional Research Board (University). Finally, the study was approved by the Research Board of the University.

\section{Variables}

The following variables were chosen for the present study, taking into consideration the feasibility criterion. All variables were tested by three skilled Asian Football Confederation (AFC) licensed coaches.

\section{Independent Variables}

\section{Selected Short Sprints with Changing Direction Tests (Non-linear)}

- $\quad$ Repeated sprint ability (RSA) mean time was taken as the score.

- Repeated sprint ability (RSA) best time was taken as the score.

- $\quad$ Illinois agility test (IAT).

\section{Selected Short Sprint with Linear Direction Test}

20 meter sprint test.

\section{Dependent Variable}

Mor-Christian dribbling ability test.

\section{Repeated Sprint Ability (RSA) Test}

The present study administers the Repeated Sprint Ability (RSA) test as proposed by Rampinini and his team. ${ }^{20}$ Only two scores; RSA mean , RSA $_{\text {best }}$, were calculated from the RSA test and these scores were counted as different variables in the study. Before the RSA test, all participants had a dynamic warm-up of 10 min of low-intensity running with some acceleration run. The test consisted of six $40 \mathrm{~m}(20+20 \mathrm{~m})$ shuttle sprints separated by 20 s of passive recovery. The participants started from a line 'A' and sprinted for $20 \mathrm{~m}$ then touched a line 'B' marked on the other side with a foot of the player and returned to the starting line ' $\mathrm{A}$ ' as fast as possible to cross the line. After 20s of passive recovery, the players had to perform the same for six times. ${ }^{20,21}$

\section{Illinois Agility Test}

The Illinois agility test was evaluated to measure acceleration, deceleration, turn in different directions, and run at different angles. ${ }^{22}$ On the "go" command, the participants sprinted 10m and turned back to the starting line. After returning to the starting line, they swerved in and out of four cones, completing two $10 \mathrm{~m}$ sprints to finish the agility course. The fastest value obtained from two trials with $5 \mathrm{~min}$ recovery inbetween was used as the agility score. The time taken to complete agility run was measured using a Casio digital stopwatch (HS-70W-1DF, Casio Electronics Co, Ltd, China).

\section{Meter Sprint Test}

Players began each test sprint from a static starting position with their front foot placed on the starting line. They were instructed to sprint across the 20 -meter range as quickly as possible in a linear way. Timing was recorded at the closest $1 / 100^{\text {th }}$ of a second. The time taken to complete each sprint was measured using a Casio digital stopwatch (HS-70W-1DF, Casio Electronics Co, Ltd, China).

\section{Mor-Christian Dribbling Test}

To evaluate the soccer dribbling ability, the Mor and Christian General Soccer Ability Skill Test (dribbling) was applied. ${ }^{23}$ The participant dribbles a ball in a round course with a diameter of 20 yards on the 'Go' command. The participant dribbles as quickly as possible between the 12 cones placed around the circle. The time taken to complete each Mor-Christian dribbling course was measured using the Casio digital stopwatch (HS-70W-1DF, Casio Electronics Co, Ltd, China).

\section{Statistical Procedure}

The data is expressed as a mean and SD. The state of normal variation was confirmed using the Shapiro-Wilk W-test prior to the use of the parametric tests. To find out a correlation between independent variables that are $\mathrm{RSA}_{\text {mean }}$ time, $\mathrm{RSA}_{\text {best }}$ time, Illinois agility test, $20 \mathrm{~m}$ sprint and dependent variable that was Mor-Christian dribbling ability test, the product moment method of correlation was used. Secondly to study the joint contribution of independent variables and dependent variable multiple correlations were used. Finally for predicting independent variables and dependent variable a multiple regression equation was formulated.

\section{RESULTS}

The procedure was completed by 60 male soccer players (Mean age $=16.65, \mathrm{SD} \pm 1.36$ years) and used for statistical analysis of their outcomes (Table 1).

\section{Dribbling Skill and Change of Direction (COD) Sprints}

Researchers found connections between Mor-Christian dribbling test performance and selected COD sprints. The results show that the

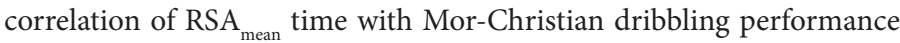
has a statistically significant positive moderate correlation (status determined using the modified scale by Hopkins, n.d.) with ' $r$ ' value of $0.561^{*}$ and $p$-value of $3.1 \mathrm{E}-06$. The result also showed that correlation of RSA best time with Mor-Christian dribbling performance has a statistically significant positive moderate correlation with ' $r$ ' value of $0.516^{*}$ and $p$-value of $2.4 \mathrm{E}-05$. The result moreover, showed that correlation of Illinois agility test with Mor-Christian dribbling performance has a statistically significant positive moderate correlation with ' $r$ ' value of $0.391^{\star}$ and $p$-value of 0.00 . Further, researchers revealed joint contribution of COD sprints (RSA mean $_{\text {time, }} \mathrm{RSA}_{\text {best }}$ time, Illinois agility test) in determining soccer dribbling skill performance (Table 2). Table 2 indicates a moderate level relationship was found between Mor-Christian dribbling performance and selected COD sprints as a coefficient of multiple correlations was found $0.598^{\star}$ which is higher than the tabulated value $r 0.05=0.25, \mathrm{~d}_{f}=58$.

\section{Dribbling Skill and Linear Sprint}

To showed connection between Mor-christian dribbling test performance and selected linear sprint researchers used product moment method of

\begin{tabular}{|c|c|}
\hline Test Protocol & Mean \pm SD and Unit $=$ Sec. \\
\hline Age (years) & $16.65, \mathrm{SD} \pm 1.36$ \\
\hline Stature $(\mathrm{cm})$ & $169.1, \mathrm{SD} \pm 4.9$ \\
\hline Body Mass (kg) & $58.5, \mathrm{SD} \pm 4.52$ \\
\hline $\mathrm{RSA}_{\text {mean }}$ time & $7.587, \mathrm{SD} \pm 0.255$ \\
\hline $\mathrm{RSA}_{\text {best }}$ time & $7.205, \mathrm{SD} \pm 0.277$ \\
\hline Illinois Agility Test & $16.529, \mathrm{SD} \pm 0.970$ \\
\hline 20 Meter Sprint & $3.406, \mathrm{SD} \pm 0.268$ \\
\hline Mor-Christian Dribbling Test & $15.132, \mathrm{SD} \pm 1.709$ \\
\hline
\end{tabular}


correlation. The results display that the correlation of $20 \mathrm{~m}$ linear sprint with Mor-Christian dribbling performance has a statistically nonsignificant positive small correlation with ' $r$ ' value of 0.208 and $p$-value of 0.109 (Table 3 ).

\section{Joint Contribution of Various Sprints in Determining Dribbling Skill}

Present researchers revealed joint contribution of various sprints

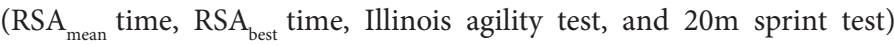
in determining soccer dribbling skill performance (Table 4). Table 4 indicates a high-level relationship was found between Mor-Christian dribbling performance and various sprints as coefficient of multiple correlations was found $0.604^{*}$ which is higher than the tabulated value $\mathrm{r} 0.05=0.25, \mathrm{~d}_{f}=58$.

The researchers also found ' $R$ ' square value is 0.365 and $R^{2}$ adj value is 0.318 . The regression coefficients developed which is as follows:

Dribbling Ability $=-16.685+2.294 \times\left(\mathrm{RSA}_{\text {mean }}\right)+1.015 \times\left(\mathrm{RSA}_{\text {best }}\right)+$ $0.304 \times$ (Illinois agility $)+0.604 \times(20 \mathrm{~m}$ sprint $)$

The above regression equation is the value of the $R^{2}$ adj is 0.318 . In other words, the selected four Variables ( $\mathrm{RSA}_{\text {mean }}$ time, $\mathrm{RSA}_{\text {best }}$ time, Illinois agility test, and $20 \mathrm{~m}$ sprint) in this regression equation explain $31.8 \%$ of the total variability in the dribbling performance.

\section{DISCUSSION}

The present study investigated the relationship between soccer dribbling ability and selected short sprint timing in a group of national youth soccer players. The key finding from this study was that the selected COD of the sprint was more significantly correlated with the dribbling performance. This may be due to the fact that the movement nature of the dribbling is close to the changing direction of the sprinting process. Therefore, in the actual soccer world as we have experienced, the degree of that relationship can also have an impact on precise ball control and beating the opponent. In our study, we also found that the correlation between linear directions of sprinting and dribbling performance was low. Such disparity in the study findings may be due to the fact that the participants mix (attacker and defender). However, dribbling a ball is performed by moving it with the feet and the moving action with every step helps a player to control the ball more. ${ }^{24}$ A player often performs this activity during a match, which requires rapid force development, such as sprinting or rapidly changing direction. ${ }^{1}$ Similarly, Pauole

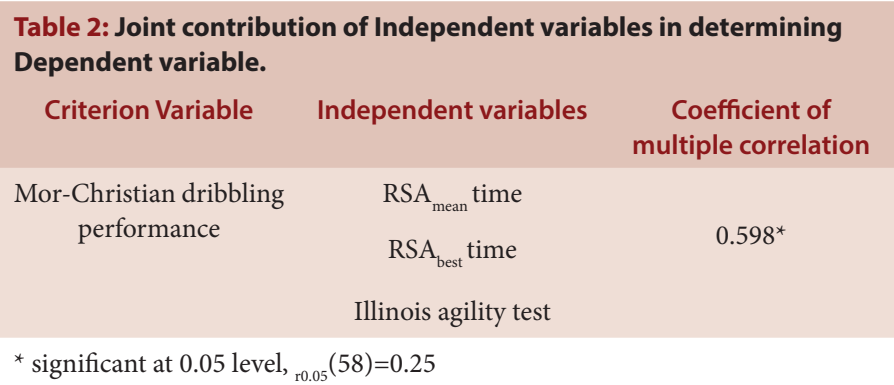

Table 3: Correlation between Independent variable and dependent
variable.
$\begin{array}{cc}\text { Independent Variable } & \text { Correlation coefficient } \\ 20 \mathrm{~m} \text { linear sprint } & 0.208\end{array}$

${ }^{*}$ significant at 0.05 level, $_{\mathrm{r} 0.05}(58)=0.25$

\section{Table 4: Joint contribution of Independent variables in determining} Dependent variable.

$\begin{array}{ccc}\text { Criterion Variable } & \text { Independent variables } & \begin{array}{c}\text { Coefficient } \\ \text { of multiple } \\ \text { correlation }\end{array} \\ \begin{array}{c}\text { Mor-Christian } \\ \text { dribbling performance }\end{array} & \mathrm{RSA}_{\text {mean }} \text { time } & 0.604^{*} \\ & \mathrm{RSA}_{\text {best }} \text { time } & \\ & \text { Illinois agility test } & \\ & 20 \mathrm{~m} \text { sprint test }\end{array}$

${ }^{*}$ significant at 0.05 level, ${ }_{\mathrm{r} 0.05}(58)=0.25$

et al. $(2000)^{25}$ found significant associations between success in an agility t-test and a sprint time of 40 yards in both men and women. However, the performance of the Loughborough Soccer Passing Test (LSPT) assists the multifaceted aspects of soccer ability that include precise ball control in a dynamic context. ${ }^{26}$ With this in mind, the points of contact with the ball may change continuously at any time during the ball control process. ${ }^{24}$ Thus, agility in team sports can be described as essential movements that require the player to make immediate changes in the direction of the body and move quickly. ${ }^{27}$ BenOunis et al. $(2013)^{28}$ found a positive moderate/large correlation between total performance of LSPT and linear short sprints time $\left(5 \mathrm{~m}\right.$ sprint time $=0.60^{*} ; 20 \mathrm{~m}$ sprint time $=0.58^{*} ; 30 \mathrm{~m}$ sprint time $=0.49^{*}$ ). The findings have shown that distance can have an effect on the relationship. Therefore, $5 \mathrm{~m}$ sprint time significantly associated with soccer skill performance (LSPT). We assumed that a linear short sprint distance could lead to soccer dribbling better than a linear higher sprint distance. The researchers also showed a very large positive correlation between the LSPT and the COD of short sprints (Agility- $15 \mathrm{~m}=0.75^{\star}$ ), (Illinois agility test $=0.72^{\star}$ ). Although previous research has shown that the change in direction of the sprint is highly correlated with the successful performance of team sports. ${ }^{29,30}$ Research carried out by Loturco et al. (2019) ${ }^{31}$ found that, soccer players with higher maximum acceleration rates can jump higher, sprint quicker (over short distances) and achieve higher COD of short sprints than their slower counterparts. Likewise, the present study also identified the relationship between field-based linear and COD of short sprints with field-based dribbling performance in soccer. Thus, when developing dribbling performance, coaches may give priority to work based on a change in direction short sprint. Similarly, repeated sprint ability (RSA) is another significant COD of sprint that is moderately associated with dribbling performance. Present study has shown that both RSA

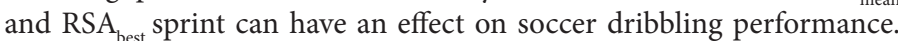
In addition, multiple correlations was computed in order to assess the combined contribution of $\mathrm{RSA}_{\text {mean }}$ time, $\mathrm{RSA}_{\text {best }}$ time, Illinois agility test and $20 \mathrm{~m}$ sprint timing in relation to dribbling ability in soccer. A high-level relationship ' $r$ ' value of $0.604^{*}, p$-value of 0.00 , at 0.05 level of confidence with 58 degrees of freedom was observed. It can, therefore, be inferred from the above analysis that the variables listed above, taken together, contribute to the soccer dribbling ability.

\section{CONCLUSION}

Sprinting has two main components-acceleration and maximum velocity. There can be no doubt that both components are very crucial for performance of dribbling. Linear, non-linear all types of short sprint have acceleration and maximum velocity. The present study showed that there would be linear and non-linear short sprints both are important to perform better dribbling in soccer. For all counts and with proven results, the emphasis should be on agility work first along with linear short sprint to increase the performance of dribbling in scientific training. It is 
believed that further research is needed to develop similar theories that included elite professional soccer players with larger sample size.

\section{Limitation}

In the absence of opponents during the Mor-Christian dribbling test, players seem to feel mental comfort, while impersonal time pressure is the only motivation for their action. This does not seem to reflect the actual actions taken by the players in the field in a match.

\section{ACKNOWLEDGEMENT}

The researchers are grateful to the soccer players who have participated in this study on a voluntary basis and to the club authorities for providing time to collect data.

\section{CONFLICT OF INTEREST}

No conflicts of interest are declared by the authors.

\section{ABBREVIATIONS}

IAT: Illinois Agility Test; RSA: Repeated Sprint Ability; BMI: Body Mass Index; SD: Standard Deviation; COD: Change of Direction; LSPT: Loughborough Soccer Passing Test.

\section{REFERENCES}

1. Bangsbo J, Mohr M, Krustrup P. Physical and metabolic demands of training and match-play in the elite football player. J Sports Sci. 2006;24(7):665-74. https:// doi.org/10.1080/02640410500482529.

2. Islam MS, De A. Functional Hamstring to Quadriceps Strength Ratio $(\mathrm{H}: \mathrm{O})$ and Hamstrings Injury of Soccer Players: A Qualitative Analysis. Orthop Sports Med Open Access J. 2018;2(2):126-32. https://doi.org/ 10.32474/OSMOAJ.2018.02.000133.

3. Papanikolaou K, Chatzinikolaou A, Pontidis T, Avloniti A, Deli CK, Leontsini D, et al. The Yo-Yo Intermittent Endurance Level 2 Test: Reliability of Performance Scores, Physiological Responses and Overload Characteristics in Competitive Soccer, Basketball and Volleyball Players. J Hum Kinet. 2019;67(1):223-33. https://doi.org/ 10.2478/hukin-2018-0091.

4. Hill-Haas S, Dawson B, Impellizzeri F, Coutts A. Physiology of Small-Sided Games Training in Football. Sports Med AuckI NZ. 2011;41(3):199-220. https:// doi.org/ 10.2165/11539740-000000000-00000.

5. Stølen T, Chamari K, Castagna C, Wisløff U. Physiology of soccer: An update Sports Med Auckl NZ. 2005;35(6):501-36. https://doi.org/ 10.2165/00007256200535060-00004.

6. Orer E. The Relationships among Acceleration, Agility, Sprinting Ability, Speed Dribbling Ability and Vertical Jump Ability in 14-Year-Old Soccer Players. Journal of Sports and Physical Education. 2016;3(2):29-34.7.

7. Fernandez-Navarro J, Fradua L, Zubillaga A, Ford PR, McRobert AP. Attacking and defensive styles of play in soccer: Analysis of Spanish and English elite teams. J Sports Sci. 2016;34(24):2195-204. https://doi.org/ 10.1080/02640414.2016.1169309.

8. Machado JC, Barreira D, Garganta J, Machado JC, Barreira D, Garganta J. The influence of match status on attacking patterns of play in elite soccer teams. Rev Bras Cineantropometria Amp Desempenho Hum. 2014;16(5):545-54. https://doi.org/ 10.5007/1980-0037.2014v16n5p545

9. Bloomfield J, Polman R, O'Donoghue P. Physical demands of different positions in FA Premier League soccer. J Sports Sci Med. 2007;6(1):63-70.
10. Joo CH, Seo DI. Analysis of physical fitness and technical skills of youth soccer players according to playing position. J Exerc Rehabil. 2016;12(6):548-52 https://doi.org/ 10.12965/jer.1632730.365.

11. Ghosh SN, De A, Mondal S. Stress hormones and sports performance: A critical analysis. Int J Physiol Nutr Phys Educ. 2018;3(1):1752-7.

12. Roy T, De A, Nandi DSC. A study on mental toughness in relation to agility and reaction ability among female kho kho players. Int J Home Sci. 2016;2(3):406-9.

13. Alanazi H. Relationships between Illinois Agility Test and Reaction Time in Male Athletes. Swed J Sci Res. 2015;1;2.

14. Bishop D, Spencer M, Duffield R, Lawrence $S$. The validity of a repeated sprint ability test. J Sci Med Sport. 2001;4(1):19-29. https://doi.org/ 10.1016/s14402440(01)80004-9

15. Haugen T, Tønnessen E, Hisdal J, Seiler S. The role and development of sprinting speed in soccer. Int J Sports Physiol Perform. 2014;9(3):432-41. https://doi.org/ 10.1123/ijspp.2013-0121.

16. Faude $\mathrm{O}$, Koch $\mathrm{T}$, Meyer T. Straight sprinting is the most frequent action in goa situations in professional football. J Sports Sci. 2012;30(7):625-31. https://doi. org/ 10.1080/02640414.2012.665940.

17. Burgess DJ, Naughton G, Norton KI. Profile of movement demands of national football players in Australia. J Sci Med Sport. 2006;9(4):334-41.

18. Vigne G, Gaudino C, Rogowski I, Alloatti G, Hautier C. Activity Profile in Elite Italian Soccer Team. Int J Sports Med. 2010;31(05):304-10. https://doi.org/ 10.1055/s-0030-1248320.

19. Islam MS. Introducing drone technology to soccer coaching. Int J Sports Sci Phys Educ. 2020;5(1):1-4. https://doi.org/ 10.11648/j.ijsspe.20200501.11

20. Rampinini E, Bishop D, Marcora SM, Ferrari BD, Sassi R, Impellizzeri FM. Validity of simple field tests as indicators of match-related physical performance in top-level professional soccer players. Int J Sports Med. 2007;28(3):228-35. https://doi.org/

21. Islam MS, Kundu B, Saha S. Relationship between repeated sprint ability and accuracy of soccer shooting performance in young players. Eur J Phys Educ Sport Sci. 2019; 5(11):95-104. https://doi.org/10.5281/zenodo.3381127.

22. Getchell B. Physical fitness: A way of life. $2^{\text {nd }}$ Ed. New Jersey: John Wiley and Sons, Inc. 1979.23.

23. Mor D, Christian V. The development of a skill test battery to measure general soccer ability. NCJ Health Phys Ed. 1979;15(1):30-9.

24. Luongo AM. Soccer Drills: Skill-Builders for Field Control. Jefferson, North Carolina and London: McFarland and Company. 2000;32.

25. Pauole K, Madole K, Garhammer J, Lacourse M, Rozenek R. Reliability and Validity of the T-Test as a Measure of Agility, Leg Power and Leg Speed in CollegeAged Men and Women. J Strength Cond Res. 2000;14(4):443-50. https://doi. org/10.1519/00124278-200011000-00012.

26. Ali A, Williams C, Hulse M, Strudwick A, Reddin J, Howarth L, et al. Reliability and validity of two tests of soccer skill. J Sports Sci. 2007;25(13):1461-70 https://doi.org/ 10.1080/02640410601150470.

27. Farrow D, Young W, Bruce L. The Development of a Test of Reactive Agility for Netball: A New Methodology. J Sci Med Sport. 2005;8(1):52-60. https://doi.org/ 10.1016/S1440-2440(05)80024-6.

28. BenOunis O, BenAbderrahman A, Chamari K, Ajmol A, BenBrahim M, Hammouda $A$, et al. Association of short-passing ability with athletic performances in youth soccer players. Asian J Sports Med. 2013;4(1):41-8. https://doi.org/ 10.5812/asjsm.34529

29. Brughelli M, Cronin J, Levin G, Chaouachi A. Understanding change of direction ability in sport: A review of resistance training studies. Sports Med Auck NZ. 2008;38(12):1045-63. https://doi.org/10.2165/00007256-200838120-00007.

30. Sheppard JM, Young WB. Agility literature review: Classifications, training and testing. J Sports Sci. 2006;24(9):919-32. https://doi.org/ 10.1080/02640410500457109.

31. Loturco I, Pereira LA, Freitas TT, Alcaraz PE, Zanetti V, Bishop C, et al. Maximum acceleration performance of professional soccer players in linear sprints: Is there a direct connection with change-of-direction ability?. Plos One. 2019;14(5):e0216806. https://doi.org/ 10.1371/journal.pone.0216806.

Cite this article : Islam MS, Kundu B. Association of Dribbling with Linear and Non-linear Sprints in Young Soccer Players of Bangladesh. Int J Med Public Health. 2020;10(3):100-3. 